\title{
Protease-Activated Receptor-Mediated Platelet Aggregation In Patients With Type 2 Diabetes On Potent P2Y12 Inhibitors
}

\section{Benjamin Panzer}

Medical University of Vienna https://orcid.org/0000-0002-7743-9797

\section{Patricia P Wadowski}

Medical University of Vienna

\section{Kurt Huber}

Sigmund Freud University

\section{Simon Panzer}

Medical University of Vienna

Thomas Gremmel ( $\nabla$ thomas.gremmel@meduniwien.ac.at)

Medical University of Vienna https://orcid.org/0000-0001-9554-7292

\section{Research Article}

Keywords: acute coronary syndrome, diabetes, dual antiplatelet therapy, platelet thrombin receptors, prasugrel, ticagrelor,

Posted Date: November 3rd, 2021

DOI: https://doi.org/10.21203/rs.3.rs-1037016/v1

License: (c) (i) This work is licensed under a Creative Commons Attribution 4.0 International License. Read Full License 


\section{Abstract}

Background: Dual antiplatelet therapy is a cornerstone in the secondary prevention of ischemic events following percutaneous coronary intervention $(\mathrm{PCl})$ with stent implantation. The new, more potent adenosine diphosphate (ADP) $\mathrm{P}_{2} \mathrm{Y}_{12}$ receptor inhibitors prasugrel and ticagrelor have been shown to improve patients' outcomes. Whether or not these drugs have equal efficacy in diabetic as in non-diabetic individuals is disputed. Furthermore, platelets can be activated by thrombin, which is, at least in part, independent of ADP-inducible activation. Protease-activated receptor (PAR)-1 and -4 are thrombin receptors on human platelets activated by the agonists SFLLRN and AYPGKF, respectively. In the current study, we sought to compare the in vitro efficacy of prasugrel $(n=121)$ and ticagrelor $(n=99)$ to inhibit PAR-mediated platelet activation in patients with type 2 diabetes $(n=55)$.

Materials and Methods: We compared $\mathrm{P}_{2} \mathrm{Y}_{12}, \mathrm{PAR}-1$ - and PAR-4-mediated platelet aggregation as assessed by multiple electrode platelet aggregometry between prasugrel- and ticagrelor-treated patients without and with type 2 diabetes who underwent acute $\mathrm{PCl}$.

Results: There were no significant differences of on-treatment platelet aggregation in response to ADP, SFLLRN and AYPGKF between patients on prasugrel or on ticagrelor. Diabetic and non-diabetic patients responded equally. There was no significant correlation between either; ADP-, SFLLRN-, or AYPGKFinducible platelet aggregation and levels of $\mathrm{HbA} 1 \mathrm{c}$ or the body mass index. However, we observed patients with high residual platelet reactivity to SFLLRN and AYPGKF in all cohorts.

Conclusion: Prasugrel and ticagrelor inhibit platelet aggregation in diabetic and non-diabetic patients to a similar extent.

\section{Introduction}

The world health organization lists cardiovascular disease as the main cause of death in industrialized countries. Patients with diabetes are at particular risk. They frequently suffer from coronary artery disease often resulting in myocardial infarction $(\mathrm{MCl})$. Accordingly, many diabetics need to undergo percutaneous coronary intervention (PCl) with stent implantation. Secondary prevention following acute $\mathrm{PCl}$ comprises dual antiplatelet therapy (DAPT) with aspirin and one of the newer potent ADP P2Y 12 receptor blockers prasugrel or ticagrelor.

Clinical studies indicate, however, that despite state-of-the art DAPT approximately $10 \%$ have additional ischemic events $[1,2,3]$. Whether prasugrel or ticagrelor are more advantageous following acute $\mathrm{PCl}$ is a matter of ongoing debate $[2,4,5,6]$, and in particular for patients with type 2 diabetes, this question cannot be definitively answered by clinical outcome data, so far. The ISAR-React 5 trial revealed no significant differences between the two drugs with respect to the 1-year outcome comprising $\mathrm{MCl}$, death, or ischemic stroke in diabetic patients, but prasugrel to be the better choice over ticagrelor in the overall study population [2]. Further analyses of this population confirmed the efficacy of ticagrelor to be comparable 
with that of prasugrel in diabetics [7]. In line with these data, ticagrelor and prasugrel have been found to be similarly effective in another cohort. [8].

A variety of conditions may, particularly in diabetics, lead to an impaired response to antiplatelet therapy. First, platelet turnover may be accelerated in diabetes, and therefore young platelets that are naïve to inhibitory drugs may be more present in the circulation [9], particularly if administered once (prasugrel) versus twice daily (ticagrelor). Second, the enteric resorption of any drug can be affected in diabetes [10]. Therefore, the required in vivo concentration of the drug to achieve platelet inhibition may not be reached. Thereby, resorption may differ from one drug to the next. Third, prasugrel but not ticagrelor needs to be metabolized to become a potent platelet inhibitor but metabolism can be affected in diabetes [11]. Fourth, alterations of the platelet membrane due to hyperglycemia and failure of insulin to inhibit platelet signaling may be responsible for an increased reactivity to ADP $[12,13]$. Fifth, other clinical conditions known to be associated with high on-treatment residual platelet reactivity to ADP (HRPR ADP), which are frequent in diabetic patients might play a role, like. kidney failure [14], high BMI [15], inflammation [16], drug-drug interactions [11]. These conditions may affect the potency of one drug more than of the other one.

Alternatively, adverse ischemic outcomes after PCl may be attributable to intact platelet aggregation via the human thrombin receptors protease-activated receptor (PAR)-1 and PAR-4 $[17,18,19,20]$, overcoming $\mathrm{P}_{2} \mathrm{Y}_{12}$ inhibition. Thrombin is a very strong endogenous platelet agonist [18] and its ongoing generation has been particularly recognized in diabetes and/or obese patients [21,22].

Thrombin-mediated platelet activation is not specifically targeted by current state-of-the-art DAPT with aspirin and a potent $P 2 \mathrm{Y}_{12}$ antagonist following $\mathrm{MCl}$, and may therefore reflect $\mathrm{P} 2 \mathrm{Y}_{12}$-independent platelet activation.

We therefore evaluated platelets' in vitro response to PAR-1 and -4, the two important thrombin receptors on human platelets, in diabetic patients receiving either prasugrel or ticagrelor after $\mathrm{PCl}$. Differences between the two drugs may affect the treatment of diabetic patients following acute $\mathrm{PCl}$.

\section{Patients}

The study population included 220 consecutive patients with MI, receiving DAPT with aspirin (loading dose of $250 \mathrm{mg}$, thereafter $100 \mathrm{mg}$ once daily), and either prasugrel (loading dose of $60 \mathrm{mg}$, thereafter 10 mg once daily, $n=121$ ), or ticagrelor (loading dose of $180 \mathrm{mg}$, thereafter $90 \mathrm{mg}$ twice daily, $\mathrm{n}=99$ ) after acute $\mathrm{PCl}$ and stenting. There were 165 non-diabetic patients and 55 patients with diabetes type 2 . Diabetes was based on the patients' history, a HbA1c value $>6.5 \%$ and regular anti-diabetic therapy. The selection of the respective $\mathrm{P}_{2} \mathrm{Y}_{12}$ inhibitor was at the discretion of the attending physician. All individuals were Caucasians from the Viennese urban area. All patients gave their written informed consent for participation. We excluded patients who had any major surgery during the last week before enrollment, or treatment with either vitamin $\mathrm{K}$ antagonists (phenprocoumon, acenocoumarol, warfarin), or rivaroxaban, apixaban, dabigatran, or edoxaban, respectively. Moreover, patients were excluded if they were taking 
nonsteroidal anti-inflammatory drugs, ticlopidine, or dipyridamole. We also excluded patients with known bleeding disorders, severe hepatic failure, known qualitative defects in platelet function, a history of heparin-induced thrombocytopenia, or malignant myeloproliferative disorders. Patients were not eligible if they had a platelet count $<100000$ or $>450000 / \mu \mathrm{L}$, or a hematocrit $<30 \%$.

The study was approved by the Ethics Committee of the Medical University of Vienna, in accordance with the declaration of Helsinki and its later amendments.

\section{Materials And Methods}

Blood samples were obtained median 72 hours (range 66 hours to 74 hours) after $\mathrm{PCl}$, when both Prasugrel and Ticagrelor were at, or approached the steady state [23,24]. A butterfly needle (21-gauge, 0.8 × 19 mm; Greiner Bio-One, Kremsmünster, Austria) was inserted by aseptic venipuncture into an antecubital vein. All blood samples were collected by the same physician. Periprocedural platelet activation was avoided by discharging the first $3 \mathrm{~mL}$ of blood. Blood samples were collected in hirudinecoated tubes (Roche Diagnostics, Mannheim, Germany), which then were immediately gently inverted. All samples were investigated by whole blood impedance aggregometry (multiple electrode aggregometry, MEA), as previously described $[25,26]$. One Multiplate test cell contains 2 independent sensor units and 1 unit consists of 2 silver-coated highly conductive copper wires with a length of $3.2 \mathrm{~mm}$. After dilution (1:2 with $0.9 \% \mathrm{NaCl}$ solution) of hirudin-anticoagulated whole blood and stirring in the test cuvettes for 3 minutes at $37^{\circ} \mathrm{C}$, the agonists ADP (P2Y 12 agonist, $6.5 \mu \mathrm{mol} / \mathrm{L}$ ), SFLLRN (PAR-1 agonist, $32 \mu \mathrm{mol} / \mathrm{L}$ ) or AYPGKF (PAR-4 agonist, $645 \mu \mathrm{mol} / \mathrm{L}$ ), all from Roche Diagnostics), were added and aggregation was continuously recorded for six minutes. The respective concentrations of agonists have been established in our laboratory [27]. The adhesion of activated platelets to the electrodes led to an increase of impedance, which was detected for each sensor unit separately and transformed to aggregation units (AU) that were plotted against time. The AU at 6 minutes were used for calculations. The thresholds for HRPR ADP, HRPR SFLLRN and HRPR AYPGKF were >47 AU [28], >71AU, and >54 AU, respectively [27].

\section{Statistical analysis}

We used the Statistical Package for Social Sciences (SPSS version 24.0; SPSS, Chicago, IL) to conduct all statistical analyses. Continuous data are shown as median and interquartile ranges whereas categorical data are depicted as numbers and percentages. The non-parametric Mann-Whitney U-test was used to assess differences between continuous variables. The chi- square test was used to calculate differences between categorical values. Spearman's correlation was used to evaluate correlations. Two-sided $P$ values $<0.05$ were considered statistically significant.

\section{Results}

Clinical, laboratory and procedural characteristics of patients with diabetes type 2 and non-diabetic patients receiving prasugral or ticagrelor are shown in Table 1. 
The study cohort comprised 121 patients on prasugrel and 99 patients on ticagrelor. In the prasugrel and the ticagrelor group 26 and 29 patients had type 2 diabetes, respectively. Diabetic patients treated with either prasugrel or ticagrelor were younger than non-diabetic individuals $(P=0.03$, and $P=0.05$ respectively), indicating their earlier onset of atherosclerosis. Patients on ticagrelor had significantly higher serum creatinine levels $(P<0.001)$. As expected, diabetic patients in both, prasugrel and ticagrelor groups, had significantly higher HbA1c levels $(P<0.001)$.

\section{Residual platelet aggregation in response to ADP/ SFLLRN / AYPGKF}

We first evaluated residual platelet response to ADP in prasugrel- and ticagrelor-treated patients. Patients on prasugrel responded similarly to platelet activation by ADP as patients on ticagrelor $(p=0.349$, Figure

1a). Among the patients on prasugrel, diabetic patients responded similarly as non-diabetic patients $(p=0.148)$. Of note, 2 non-diabetic patients had HRPR ADP as their levels of AU was $>47$, the cut-off for adequate platelet inhibition by ADP $\mathrm{P}_{2} \mathrm{Y}_{12}$ receptor antagonists. Their responses to SFLLRN was $92 \mathrm{AU}$ and $106 \mathrm{AU}$ and to AYPGKF $62 \mathrm{AU}$ and $100 \mathrm{AU}$, respectively.

Interestingly, among patients on ticagrelor, patients with type 2 diabetes had significantly lower MEA ADP $A U$ values than non-diabetic patients $(p=0.019$, Figure $1 a)$.

Patients on prasugrel responded similarly to platelet activation by SFLLRN as patients on ticagrelor $(P=0.227$, Figure $1 b)$. Furthermore, there were no significant differences regarding the response to SFLLRN between diabetic and non-diabetic patients in both treatment groups (prasugrel: $p=0.7129$, ticagrelor: $p=0.144$, Figure $1 b$ ).

Patients on prasugrel responded similarly to platelet activation by AYPGKF as patients on ticagrelor $(p=0.861$, Figure 1c). Moreover, there were no significant differences between diabetic and non-diabetic patients in both treatment groups (prasugrel: $p=0.399$, ticagrelor: $p=0.175$ Figure $1 c$ ).

In the prasugrel group 119 patients had on-treatment residual platelet reactivity below the cut-off for HRPR ADP. Of these, 51 patients (43\%) had HRPR SFLLRN and 71 (60\%) had HRPR AYPGKF. In the diabetic population we identified 12 patients (46\%) with HRPR SFLLRN and 16 patients (62\%) with HRPR AYPGKF.

All ticagrelor-treated patients had on-treatment residual platelet reactivity below the cut-off for HRPR ADP. Of these patients 30 (30\%) had HRPR SFFLRN and 55 (56\%) had HRPR AYPGKF. In the diabetic population, 7 patients (24\%) had HRPR SFLLRN and 11 patients (38\%) had HRPR AYPGKF.

As $\mathrm{P} 2 \mathrm{Y}_{12}$ inhibition also affects the response to PAR stimulation we subsequently assessed the correlations between on-treatment residual platelet reactivity in response to ADP and in response to both PAR agonists, SFLLRN and AYPGKF. Again, diabetic patients were evaluated separately from non-diabetic patients. We observed a similar correlation between the responses to ADP and SFLLRN in diabetic patients and in non-diabetic patients on prasugrel and ticagrelor (all $r=0.556, p<0.001$ ). There was also a 
significant correlation between the response to ADP and AYPGKF in diabetic patients on prasugrel and ticagrelor $(r=0.273, p=0.048)$, as well as in non-diabetic patients $(r=0.527, p=0.001)$.

The two platelet thrombin receptors PAR-1 and PAR-4 play a significant mutual role in platelet activation. Therefore, it was of interest to determine if the residual responsiveness to the specific PAR agonists SFLLRN and AYPGKF correlates similarly in diabetic patients compared to non-diabetic patients treated with prasugrel or ticagrelor. We observed significant correlations between the responses to SFLLRN and AYPGKF in diabetic patients $(r=0.711, p<0.001)$ and in non-diabetic patients $(r=0.556, p<0.001)$.

\section{Residual platelet aggregation in response to ADP/ SFLLRN / AYPGKF and the correlation to HbA1c}

Metabolic control may influence the responsiveness to DAPT. We therefore correlated levels of HbA1c, as a measure of a long-term blood glucose control, with on-treatment residual platelet aggregation in response to ADP. There was no significant correlation between levels of $\mathrm{HbA} 1 \mathrm{c}$ and the response to ADP in the study population. $(r=0.07, p>0.05$, Figure $2 a)$.

Based on the assumption that impaired diabetic control influences particularly thrombin-inducible platelet activation, we also assessed the correlation of $\mathrm{HbA} 1 \mathrm{c}$ levels with the platelet response to the PAR-1 and -4

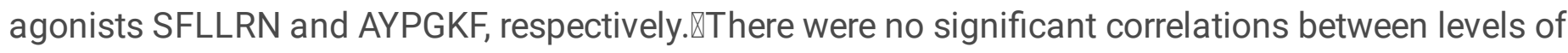
$\mathrm{HbA1c}$ and the response to SFLLRN $(r=0.09, p>0.05$, Figure $2 b)$ or the response to AYPGKF $(r=0.07$, $p>0.05$, Figure $2 c$ ) in the study population.

\section{Residual platelet aggregation in response to ADP/ SFLLRN / AYPGKF and the correlation to the BMI}

As high BMI levels may impair the response to treatment with prasugrel or ticagreleor we assessed the correlation between $\mathrm{BMI}$ and the residual response to. There was no significant correlation between levels of the $\mathrm{BMI}$ and the response to $\operatorname{ADP}(r=-0.02, p>0.05$, Figure $3 a)$ in the study population.

High levels of BMI have been associated with increased thrombin generation and PAR-1-mediated platelet aggregation [16]. We therefore anticipated a correlation between BMI and the responsiveness to the PAR-1 and PAR-4 agonists. However, there was no significant correlation between $\mathrm{BMI}$ and the response to SFLLRN ( $r=0.06, p>0.05$ Figure $3 b)$, or the response to AYPGKF ( $r=0.07, p>0.05$ Figure $3 c)$ in the study population.

\section{Discussion}

This study investigated if prasugrel and ticagrelor are equally potent in the inhibition of PAR-1- and PAR-4mediated platelet aggregation in diabetic patients. Our data show no significant differences between platelet PAR-1 and PAR-4 response in patients on prasugrel when compared to patients on ticagrelor. Diabetic and non-diabetic patients responded similarly. Moreover, the response to the agonists did not correlate with levels of $\mathrm{HbA} 1 \mathrm{c}$ or BMI. 
Prasugrel and ticagrelor inhibited the platelet response to ADP at a similar level, i.e. all patients on ticagrelor and all but 2 patients on prasugrel exhibited a residual platelet response below the internationally-agreed threshold of 47 AU for HRPR ADP. This threshold has been established based on clinical data from patients on clopidogrel therapy [28], and may therefore need to be adjusted for the newer drugs.

Our findings are in contrast to a previous report, showing stronger platelet suppression in the prasugrel than the ticagrelor group [29]. These findings were similar if samples were analyzed median 11.8 hours or 38.5 hours after loading with the respective $\mathrm{P}_{2 \mathrm{Y}_{12}}$ inhibitor [29]. Whether or not the different results in our cohort can be explained by the later time point of blood sampling, namely 72 hours after $\mathrm{PCl}$ and stent implantation in our study, remains unclear. Of note, at this later time point patients had already received either prasugrel or ticagrelor for three consecutive days, possibly representing a better steady-state after the intervention $[23,24]$. In accordance with our data ticagrelor has been found to allow a higher platelet reactivity inhibition compared to prasugrel in patients with type 2 diabetes [30].

Unexpectedly, our data show that platelets from diabetic patients are more susceptible to $\mathrm{P}_{2} \mathrm{Y}_{12}$ inhibition by ticagrelor than non-diabetics. No statistical significant differences were seen between diabetics and non-diabetics in the prasugrel group (even after exclusion of the two patients with HRPR). Prasugrel needs conversion in the liver and intestines into its active metabolite, which then binds covalently to the $\mathrm{P}_{2 \mathrm{Y}_{12}}$ receptor [31]. This biotransformation to the active substance is more likely to be impaired if metabolism is affected by diabetes. Thus, patients with diabetes who are on prasugrel may have a reduced generation of the active metabolite and consequently less platelet inhibition compared to nondiabetic patients [32,33].

In contrast to prasugrel, the cyclopentyl-triazolopyrimidine ticagrelor acts directly without prior biotransformation. While the active metabolites of prasugrel irreversibly block the $\mathrm{P}_{2 \mathrm{Y}_{12}}$ receptor, ticagrelor inhibits ADP-induced signalling reversibly in a non-competitive manner at a different binding site [34,35,36,37]. Further pointing at in vitro differences between prasugrel and ticagrelor- inhibited platelets are previous findings that ticagrelor exerts a stronger inhibitory effect on toll-like receptor- $1 / 2$ and PAR mediated platelet activation in acute coronary syndrome than prasugrel [38]. As diabetic patients may have a higher inflammatory status and thus cytokine storms with up-regulated TLR receptors, it may be speculated that ticagrelor, but not prasugrel, "calms" the innate immune system in diabetics thereby being particularly effective in inhibiting their platelets. In line with these findings, Jeong et al. found a significant reduction of inflammatory markers in the ticagrelor group when comparing prasugrel with ticagrelor in a randomized manner, suggesting more clinical benefit by ticagrelor in this population [39].

It has been shown that diabetics have a higher thrombin generation potential than non-diabetic patients [21]. Further, it is possible that ongoing thrombin generation is a main reason for recurrent events despite potent inhibition of ADP-inducible platelet activation. In detail, platelets, which have been successfully inhibited for ADP-inducible activation, may still be responsive to platelet activation via PAR. 
We therefore assumed that particularly platelets from diabetic patients are poised for activation by thrombin and the exogenous addition of the respective platelet agonists for PAR-1 and PAR-4 will reveal higher activation values in diabetic compared to non-diabetic patients. However, in the overall cohort, we saw no difference in the response to the PAR-directed agonists SFLLRN or AYGPKF in prasugrel-versus ticagrelor-treated patients. Further analyses revealed also no difference between diabetic and nondiabetic patients with the two platelet inhibitors indicating their equal potency to suppress platelet activation via the two PAR receptors. In our in vitro investigations, we observed a significant correlation between platelet response to ADP and platelet response to both PAR agonists. This correlation was similar in diabetic and non-diabetic individuals. The observation indicates that a very potent inhibition of ADP-inducible platelet activation leads also to inhibition of thrombin-inducible platelet activation. It shall be emphasized, that almost all patients in the prasugrel cohort and all patients on ticagrelor had an adequately inhibited response to ADP. However, among these patients who adequately responded to $\mathrm{P}_{2} \mathrm{Y}_{12}$ inhibition by prasugrel or ticagrelor we identified a number of individuals who still responded to activation by either SFLLRN or AYGPKF or both. The latter ones were seen equally frequent in the diabetic as in the non-diabetic cohort. We therefore conclude that both drugs were equally potent platelet inhibitors of ADP-inducible platelet activation, but less potent to inhibit PAR- mediated platelet activation, in diabetic and non-diabetic patients.

Metabolic control is beneficial in diabetic patients for their response to antiplatelet therapy. Clinically, ticagrelor was shown to reduce the primary endpoint, all-cause mortality, and stent thrombosis in patients with levels of HbA1c above the median [40]. High BMI levels have been associated with high thrombin generation potential [22]. We followed the hypothesis, that ongoing thrombin generation is responsible for increased platelet responsiveness to PAR-1- and PAR-4-mediated platelet activation. Thereby, we investigated, if the platelet responsiveness to PAR-1 and PAR-4 stimulation is correlated with levels of $\mathrm{HbA} 1 \mathrm{c}$, as an indicator of long-term metabolic control, and with $\mathrm{BMI}$, a rough overall indicator of impaired metabolism, which can be associated with inflammation [22]. The data from our study indicate that neither HbA1c levels nor BMI were associated with the response to platelet activation by the two PAR agonists. Apparently, the potency of the newer inhibitors prasugrel and ticagrelor can overcome the unfavorable conditions, like poor diabetic control or high BMI, that have been associated with a reduced platelet inhibition in the past.

\section{Study Limitations}

Each patients' sample was analyzed only once. The laboratory staff was blinded to the origin of the samples. Samples were only obtained at a single time point, namely 72 hours after $\mathrm{PCl}$. We cannot rule out that results would be slightly different, if samples are analyzed at other time points.

We cannot rule out that the non-diabetic cohort included a few patients with pre-diabetes. However, we were interested to investigate differences between overt diabetes and non-diabetes. 
Our study was not designed to assess clinical outcomes. The aim of the study was the evaluation of the in vitro response to PAR agonists despite potent suppression of ADP-inducible platelet activation in diabetic patients. According to our data a considerable number of patients show platelet activation by PAR in vitro, irrespective if diabetic or not, without a significant difference between the patients receiving prasugrel and those receiving ticagrelor. Whether or not individuals, who still respond to PAR-mediated platelet aggregation, can benefit from inhibition of thrombin-mediated platelet activiation, e.g. with the PAR-1 inhibitor vorapaxar [41] or the thrombin inhibitor dabigatran $[42,43]$ needs to be evaluated in clinical trials. However, a therapeutic regimen aimed at PAR inhibition may be considered only for very high-risk patients with defined residual response to PAR-mediated platelet reactivity.

\section{Conclusion}

To the best of our knowledge, this is the first study addressing PAR-1 and PAR-4 mediated in vitro platelet aggregation in diabetic patients on DAPT with either prasugrel or ticagrelor. The results obtained with the two $\mathrm{P}_{2} \mathrm{Y}_{12}$ blockers were similar, without any difference between diabetic and non-diabetic patients.

Moreover, levels of metabolic control, as estimated by $\mathrm{HbA} 1 \mathrm{c}$ and BMI shared no correlation with residual platelet response to ADP, or the PAR-1 and PAR-4 specific agonists.

\section{Abbreviations}

ADP adenosine diphosphate

AU aggregation units

AYPGKF Ala-Tyr-Pro-Gly-Lys-Phe

BMI body mass index

DAPT dual anti-platelet therapy

HRPR high residual platelet reactivity

MEA multiple electrode aggregometry

MI myocardial infarction

PAR-1 protease-activated receptor-1

PAR-4 protease-activated receptor-4

$\mathrm{PCl} \quad$ percutaneous coronary intervention

SFLLRN Ser-Phe-Leu-Leu-Arg-Asn 


\section{Declarations}

\section{Ethics approval and consent to participate}

The study was approved by the Ethics Committee of the Medical University of Vienna, in accordance with the declaration of Helsinki and its later amendments.

\section{Consent for publication}

All patients gave their written informed consent for participation.

\section{Data availability}

Raw data generated and/or analyzed during the current study are available from the corresponding author on reasonable request.

\section{Acknowledgments}

This work was part of the doctorial thesis of BP. The authors thank Beate Eichelberger for her expertise and assistance in the laboratory work.

\section{Competing Interests}

All authors declare that there are no relationships or activities that might bias, or be perceived to bias, their work.

\section{Authors' relationships and contributions}

BP assembled data, performed statistical analyses, designed graphs and wrote the manuscript, PPW recruited the patients, assembled their clinical data, advised statistical analyses, revised the manuscript, $\mathrm{KH}$ advised the study, revised the manuscript, SP assisted in data interpretation and writing the manuscript, TG initiated and designed the study, and wrote the manuscript. All authors consented to the submission of the Manuscript in its current form.

\section{Funding}

The research was funded by the "Medical Scientific Fund of the Mayor of the City of Vienna", grant number 14016, and by the "Anniversary Fund of the Austrian National Bank", grant number 16155, to Thomas Gremmel.

\section{Availability of data}

The datasets generated during and/or analyzed during the current study are available from the corresponding author on reasonable request. 


\section{References}

1. Motovska Z, Hlinomaz O, Kala P, Hromadka M, Knot J, Varvarovsky I, Dusek J, Jarkovsky J, Miklik R, Rokyta R, et al. 1-Year Outcomes of Patients Undergoing Primary Angioplasty for Myocardial Infarction Treated With Prasugrel Versus Ticagrelor. J Am Coll Cardiol. 2018;71:371-381.

2. Schüpke S, Neumann FJ, Menichelli M, Mayer K, Bernlocher I, Wöhlre J, Richgardt G, Liebetrau C, Witzenbichler B, Antoniucci D, et al. Ticagrelor or Prasugrel in Patients with Acute Coronary Syndromes. N Engl J Med. 2019;381:1524-1534.

1. Coughlan J.J., Ayetkin A, Lahu S, Ndrepepa G, Menichelli M, Mayer K, Wöhrle J, Bernlocher I, Gewalt S, Witzenbichler B, et al. Ticagrelor or Prasugrel for Patients With Acute Coronary Syndrome Treated With Percutaneous Coronary Intervention A Prespecified Subgroup Analysis of a Randomized Clinical Trial. JAMA Cardiol 2021;6:1121-1129.

2. Jneid H. Ticagrelor or Prasugrel in Acute Coronary Syndromes - The Winner Takes It All? N Engl J Med. 2019;381:1582-1585.

3. Kubica J, Jaguszewski M. ISAR-REACT 5 - What have we learned? Cardiol J. 2019;26:427-428.

4. Crea F. Debate: Prasugrel rather than ticagrelor is the preferred treatment for NSTE-ACS patients who proceed to $\mathrm{PCl}$ and pretreatment should not be performed in patients planned for an early invasive strategy. Eur Heart J 2021;42:2973-2985.

5. Ndrepepa G, Kastrati A, Menichelli M, Neumann FJ, Wöhrle J, Bernlocher I, Richardt G, Witzenbichler B, Sibbing D, Gewalt S, et al. Ticagrelor or Prasugrel in Patients With Acute Coronary Syndromes and Diabetes Mellitus. JACC Cardiovasc Interv. 2020;13:2238-2247.

6. Jacobsen MR, Engstrøm T, Torp-Pederson C, Gislason G, Glinge C, Butt JH, Fosbøl EL, Holmvang L, Pedersen F, et al. Clopidogrel, prasugrel, and ticagrelor for all-comers with ST-segment elevation myocardial infarction. Int J Cardiol. 2021;342:15-22.

7. Janka HU, Standl E, Mehnert H. Increased platelet adenylate cyclase activity in diabetic patients with microangiography. Horm Metab Res Suppl. 1981;11:26-29.

8. Horváth VJ, Putz Z, Izbéki F, Körei AE, Gerő L, Lengyel C, Kempler P, Várkonyi T. Diabetes-related dysfunction of the small intestine and the colon: focus on motility. Curr Diab Rep. 2015;15:94.

9. Gremmel T, Panzer S. Clinical, genetic and confounding factors determine the dynamics of the in vitro response/non response to clopidogrel. Thromb Haemost. 2011;106:211-218.

10. Ferroni P, Basili S, Falco A. Platelet activation in type 2 diabetes mellitus. J Thromb Haemost . 2004;2:1282-1291.

11. Ferreira IA, Mocking Al, Feijge MA, Gorter G, van Haeften TW, Heemskerk JWM, Akkerman JWN. Platelet inhibition by insulin is absent in type 2 diabetes mellitus. Arterioscler Thromb Vasc Biol. 2006;26:417-422.

12. Gremmel T, Müller M, Steiner S, Seidinger D, Koppensteiner R, Kopp CW, Panzer S. Chronic kidney disease is associated with increased platelet activation and poor response to antiplatelet therapy. 
Nephrol Dial Transplant. 2013;28:2116-22.

13. Lee S, Eichelberger B, Kopp CW, Panzer S, Gremmel T. Residual platelet reactivity in low-dose aspirintreated patients with class 1 obesity. Vascul Pharmacol. 2021;136:106819.

14. Gremmel T, Perkmann T, Seidinger D, Koppensteiner R, Panzer S, Kopp CW, Steiner S. Differential impact of inflammation on six laboratory assays measuring residual arachidonic acid-inducible platelet reactivity during dual antiplatelet therapy. Atheroscler Thromb. 2013;20:630-645.

15. Kahn ML, Nakanishi-Matsui M, Shapiro MJ, Ishihara H, Coughlin SR. Protease-activated receptors 1 and 4 mediate activation of human platelets by thrombin. J Clin Invest. 1999;103:879-887.

16. Ofosu FA, Dewar L, Craven SJ, Song Y, Cedrone A, Freedman J, Fenton JW 2nd. Coordinate activation of human platelet protease-activated receptor- 1 and -4 in response to subnanomolar alphathrombin. J Biol Chem. 2008;283:26886-26893.

17. Gremmel T, Frelinger AL 3rd, Michelson AD. Platelet Physiology. Semin Thromb Hemost. 2016;42:191-204.

18. Duvernay MT, Temple KJ, Maeng JG, Blobaum AL, Stauffer SR, Lindsley CW, Hamm HE. Contributions of Protease-Activated Receptors PAR1 and $\triangle P A R 4$ to Thrombin-Induced GPIIbIlla Activation in Human Platelets. Mol Pharmacol. 2017;91:39-47.

19. Lee S, Ay C, Kopp CW, Panzer S, Gremmel T. Impaired glucose metabolism is associated with increased thrombin generation potential in patients undergoing angioplasty and stenting. Cardiovasc Diabetol. 2018;17:131.

20. Ay L, Kopp HP, Brix JM, Ay C, Quehenberger P, Schernthaner GH, Pabinger I, Schernthaner G. Thrombin generation in morbid obesity: significant reduction after weight loss. J Thromb Haemost. 2010;8:759-765.

21. Dobesh PP. Pharmacokinetics and pharmacodynamics of prasugrel, a thienopyridine P2Y12 inhibitor. Pharmacotherapy. 2009;29:1089-102.

22. Navarese EP, Buffon A, Kozinski M, Obonska K, Rychter M, Kunadian V, Austin D, De Servi S, Sukiennik A, Kubica J. A critical overview on ticagrelor in acute coronary syndromes. QJM. 2013;106:105-15.

23. Gremmel T, Kopp C, Seidinger D, Giurgia GA, Koppensteiner R, Steiner S, Panzer S. The formation of monocyte platelet aggregates is independent of on-treatment residual agonists'-inducible platelet reactivity. Artherosclerosis. 2009;207:608-613.

24. Gremmel T, Xhelili E, Steiner S, Koppensteiner R, Kopp CW, Panzer S. Response to antiplatelet therapy and platelet reactivity to thrombin receptor activating peptide- 6 in cardiovascular interventions:

Differences between peripheral and coronary angioplasty. Atherosclerosis. 2014;232:119-124.

25. Wadowski PP, Pultar J, Weikert C. Protease-activated receptor-mediated platelet aggregation in acute coronary syndrome patients on potent P2Y 12 inhibitors. Res Pract Thromb Haemost. 2019;3:383390. 
26. Sibbing D, Aradi D, Alexopoulus D, Ten Berg J, Bhatt DL, Bonello L, Collet JP, Cuisset T, Fanchi F, Gross $L$, et al. Updated Expert Consensus Satement on Platelet Function and Genetic Testing for Guiding P2Y12 Receptor Inhibitor Treatment in Precutaneus Coroany Intervention. JACC Cardiovasc Interv. 2019;12:1527-1537.

27. Mayer K, Bongiovanni D, Karschin V, Sibbing D, Angiolillo Dj, Schunkert H, Laugwitz KL, Schüpke S, Kastrati A, Bernlocher I. Ticagrelor or Prasugrel for Platelet Inhibition in Acute Coronary Syndrome Patients: The ISAR-REACT 5 Trial. J Am Coll Cardiol. 2020;76:2569-2571.

28. Lemesle G, Schurtz G, Bauters C, Hamon M. High on-treatment platelet reactivity with ticagrelor versus prasugrel: a systematic review and meta-analysis. J Thromb Haemost 2015;13(6):931-42.

29. Wallentin L. P2Y(12) inhibitors: differences in properties and mechanisms of action and potential $\mathbb{Q}$ consequences for clinical use. Eur Heart J. 2009;30:1964-1977.

30. Erlinge D, Varenhorst C, Braun OO, James S, Winters KJ, Jakubowski JA, Brandt JT, Sugidachi A, Siegbahn A, Wallentin L. Patients with poor responsiveness to thienopyridine treatment \or with diabetes have lower levels of circulating active metabolite, but their platelets respond normally to active metabolite added ex vivo. J Am Coll Cardiol. 2008;52:1968-1977.

31. Niijima S, Ohmori T, Kario K. Differential impact of diabetes mellitus on antiplatelet effects of prasugrel and clopidogrel. Thromb J. 2018;16:5.

32. Husted S, van Giezen JJ. Ticagrelor: the first reversibly binding oral P2Y12 receptor antagonist. Cardiovasc Ther. 2009;27:259-274.

33. VAN Giezen JJ, Nilsson L, Berntsson P, Wissing BM, Giordanetto F, Tomlinson W, Greasley PJ. Ticagrelor binds to human P2Y(12) independently from ADP but antagonizes ADP-induced receptor signaling and platelet aggregation. J Thromb Haemost. 2009;7:1556-1565.

34. Birkeland K, Parra D, Rosenstein R. Antiplatelet therapy in acute coronary syndromes: focus on ticagrelor. J Blood Med. 2010;1:197-219.

35. Aungraheeta R, Conibear A, Butler M, Kelly E, Nylander S, Mumford A, Mundell SJ. Inverse agonism at the P2Y12 receptor and ENT1 transporter blockade contribute to platelet inhibition by ticagrelor. Blood. 2016;128(23):2717-2728.

36. Wadowski PP, Weikert C, Pultar J, Lee S, Eichelberge B, Koppensteiner R, Lang IM, Panzer S, Gremmel T. Ticagrelor Inhibits Toll-Like and Protease-Activated Receptor Mediated Platelet Activation in Acute Coronary Syndromes. Cardiovasc Drugs Ther. 2020;34:53-63.

37. Jeong HS, Hong SJ, Cho SA, Kim JH, Cho JY, Lee SH, Joo HJ, Park JH, Yu CW, Lim DS. Comparison of Ticagrelor Versus Prasugrel for Inflammation, Vascular Function, and Circulating Endothelial Progenitor Cells in Diabetic Patients With Non-ST-Segment Elevation Acute Coronary Syndrome Requiring Coronary Stenting: A Prospective, Randomized, Crossover Trial. JACC Cardiovasc Interv. 2017;10:1646-1658.

38. James S, Angiolillo DJ, Cornel JH, Erlinge D, Husted S, Kontny F, Maya J, Nicolau JC, Spinar J, Storney RF, et al. Ticagrelor vs. clopidogrel in patients with acute coronary syndromes and diabetes: 
a substudy from the PLATelet inhibition and patient Outcomes (PLATO) trial. Eur Heart J. 2010;31:3006-3016.

39. Chaudhary R, Mohananey A, Sharma SP, Singh S, Singh A, Kondur A. Improving Outcomes in Cardiovascular Diseases: A Review on Vorapaxar. Cardiol Rev. 2021; doi:10.1097/CRD.0000000000000390.

40. Vinholt PJ, Nielsen C, Söderström AC, Brandes A, Nybo M. Dabigatran reduces thrombin-induced platelet aggregation and activation in a dose dependent manner. J Thromb Thrombolysis. 2017;44:216-222.

41. Galli M, Capodanno D, Benenati S, D'Amario D, Crea F, Andreotti F, Angiolillo DJ. Efficacy and safety of dual-pathway inhibition in patients with cardiovascular disease: a meta-analysis of 49802 patients from 7 randomized trials. Eur Heart J Cardiovasc Pharmacother. 2021; doi:10.1093/ehjcvp/pvab043

\section{Table}

Table 1: Characteristics of patients with diabetes type 2 and non-diabetic patients receiving prasugrel or ticagrelor 


\section{Demographics}

Age, y

Male sex, n (\%)

BMI, $\mathrm{kg} / \mathrm{m}^{\wedge} 2$

$55(46-62)$

$60(55-66)$

$77(81)$

20 (77)

$28(25-31)$

$28(26-30)$

\section{Medical history}

Previous MCI, $\mathrm{n}(\%)$

Hypertension, $n(\%)$

$14(15)$

$59(61)$

4 (15)

Active smoking, $\mathrm{n}(\%)$

$56(59)$

$19(73)$

$16(62)$

Stent implantation, $\mathrm{n}(\%)$

95(100)

$26(100)$

Number of stents/patient

$1(1-2)$

$1(1-2)$

\section{Laboratory data}

$\mathrm{HbAlc}, \mathrm{mmol} / \mathrm{mol}$

$36.6(33.9-38.8)$

HbA1c (\%)

$5.5(5.25-5.70)$

$54.1(42.6-69.4)$

Serum creatine, $\mathrm{mg} / \mathrm{dL}$

$0.87(0.76-1.00)$

$7.1(6.05-8.50)$

199 (166-228)

$0.92(0.80-1.09)$

Platelet count, G/L

High sensitivity $\mathrm{C}$-reactive protein,

$\mathrm{mg} / \mathrm{dL}$

White Blood Cell Count, G/L

\section{Medication}

Statins, n (\%)

Beta blockers, n (\%)

$\mathrm{ACE}$ inhibitors, $\mathrm{n}(\%)$

Calcium channel blockers, $n(\%)$

Angiotensin receptor blockers, $\mathrm{n}(\%)$

Diabetes therapy

GLP-1-Receptor-Agonists, n (\%)

Gliptins, n (\%)

Sylfonylureas, $n(\%)$

Metformin, n (\%)

Glitazones, $n(\%)$

SGLT-2 inhibitors, n (\%)
$1.26(0.73-2.60)$

$13.95(13.10-14.78)$

$8.57(7.69-10.06)$

$92(97)$

$89(94)$

$77(81)$

$7(7)$

$13(14)$

$0(0)$

$0(0)$

$0(0)$

$0(0)$

$0(0)$

$0(0)$
$198(156-237)$

$2.65(0.90-5.59)$

$13.90(13.25-14.95)$

$10.31(8.49-11.96)$

$26(100)$

$26(100)$

$23(88)$

3 (12)

4 (15)

$0(0)$

$5(19)$

3 (12)

$16(62)$

1 (4)

4 (15)

\section{Figures}


a

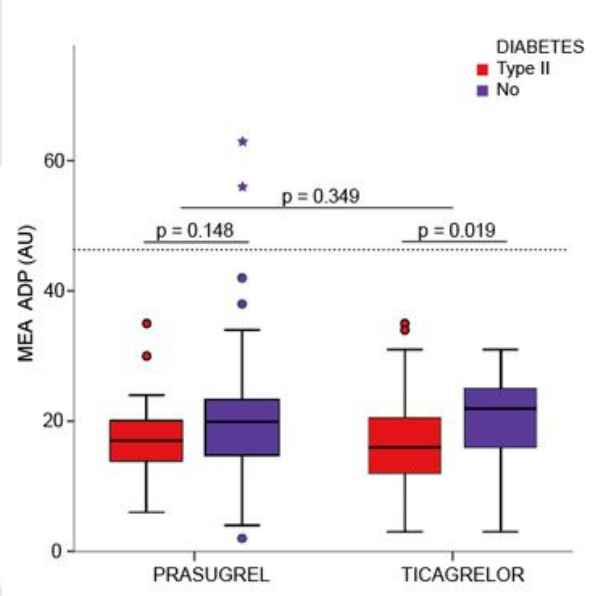

b

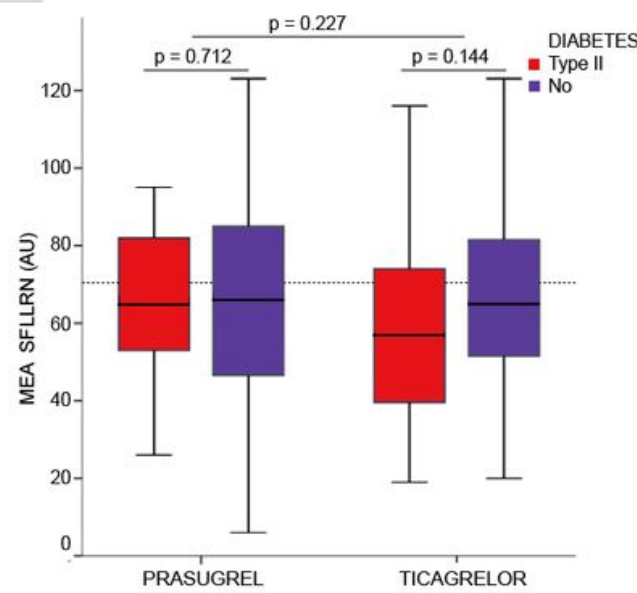

C

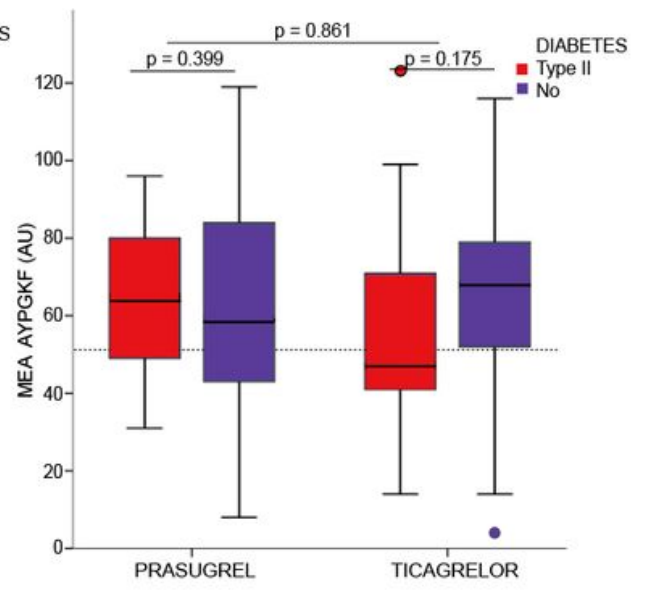

\section{Figure 1}

On-treatment residual platelet aggregation in response to (A) ADP, (B) SFLLRN and (C) AYGPKF in diabetic and non-diabetic patients receiving prasugrel or ticagrelor. The boundaries of the box show the lower and upper quartile of data. The line inside the box represents the median. Whiskers are drawn from the edge of the box to the highest and lowest values that are outside the box but within 1.5 times the boxes length. Outliers are shown by full circles and extremes by asterisk. The dotted line indicates the threshold for high on-treatment residual platelet reactivity (ADP: >47AU, SFLLRN: >71AU, AYGPKF: >54AU) $A U$, aggregation units; MEA, multiple electrode aggregometry
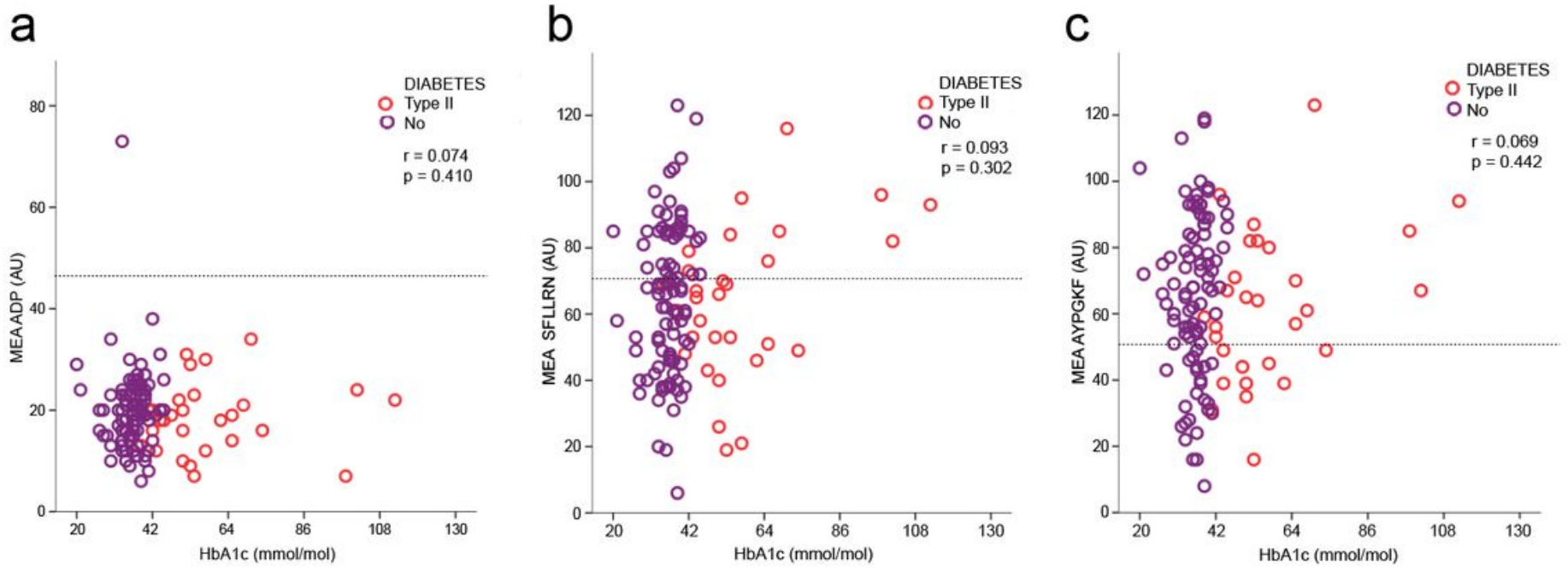

Figure 2

Correlations between $\mathrm{HbA} 1 \mathrm{c}$ and on-treatment residual platelet aggregation in response to ADP (A), SFLLRN (B) and AYGPKF (C) in diabetic and non-diabetic patients receiving prasugrel or ticagrelor. The correlation between levels of $\mathrm{HbA} 1 \mathrm{c}$ and the response to agonists in diabetic and non-diabetic patients on either prasugrel or ticagrelor. Each circle represents a single patient. The dotted line indicates the 
threshold for high residual platelet reactivity (design as in Figure 1). AU, aggregation units; MEA, multiple electrode aggregometry.
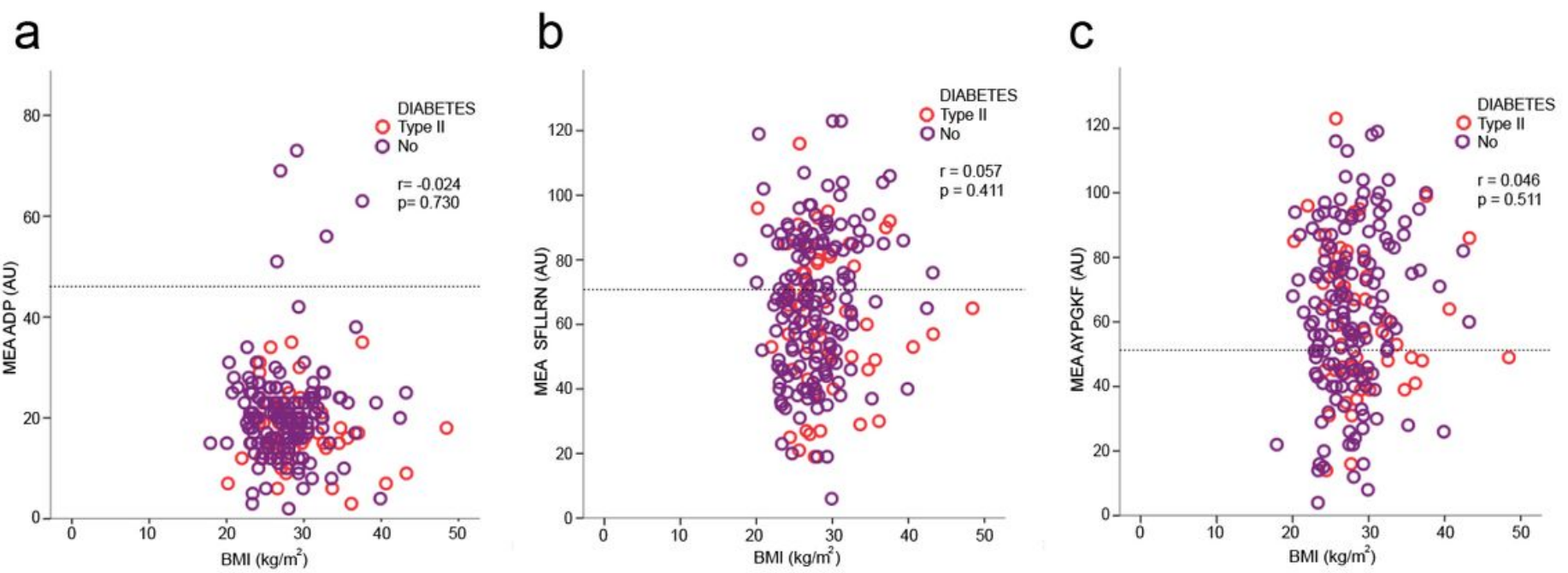

Figure 3

Correlations between $\mathrm{BMI}$ and on-treatment residual platelet aggregation in response to ADP (A), SFLLRN $(B)$ and AYGPKF (C) in diabetic and non-diabetic patients receiving prasugrel or ticagrelor. Experimental design as in Figure 2. 